\title{
Head coring for chronic calcific pancreatitis without pancreatic head mass: Short-term outcome analysis
}

\author{
Rajamahendran Rajendran, Anbalagan Amudhan, Prabhakaran R., \\ Benet Duraisamy, Rajendran Vellaisamy, Kannan D., Chandramohan S. M.
}

\begin{abstract}
Aims: Intolerable abdominal pain is the main cause which brings the patients with chronic calcific pancreatitis to the surgeon. As pancreatic head is the pacemaker of pain in chronic pancreatitiscoringouttheheadevenintheabsence of inflammatory head mass provides better pain relief. Materials and Methods: This retrospective cum prospective study analyzed the outcome of Frey procedure in chronic calcific pancreatitis patients without inflammatory head mass. Methods. For the period between 2010 and 2013 , 140 patients with chronic pancreatitis underwent Frey procedure for intractable abdominal pain. Of them 80 patients without pancreatic head
\end{abstract}

Rajamahendran Rajendran¹, Anbalagan Amudhan², Prabhakaran $\mathrm{R}^{2}$, Benet Duraisamy ${ }^{2}$, Rajendran Vellaisamy ${ }^{3}$, Kannan $\mathrm{D}^{4}$, Chandramohan $\mathrm{SM}^{5}$

Affiliations: ${ }^{1}$ Post Graduate in Surgical Gastroenterology, Institute of Surgical Gastroenterology, Rajiv Gandhi Government General Hospital, Chennai, Tamil Nadu, India; ${ }^{2}$ Assistant Professor in Surgical Gastroenterology, Institute of Surgical Gastroenterology, Rajiv Gandhi Government General Hospital, Chennai, Tamil Nadu, India; ${ }^{3}$ Post graduate in Surgical Gastroenterology, Institute of Surgical Gastroenterology, Rajiv Gandhi Government General hospital, Chennai, Tamil Nadu, India; ${ }^{4}$ Professor of Surgical Gastroenterology, Institute of Surgical Gastroenterology, Rajiv Gandhi Government General Hospital, Chennai, Tamil Nadu, India; ${ }^{5}$ Director of Surgical Gastroenterology, Institute of Surgical Gastroenterology, Rajiv Gandhi Government General Hospital, Chennai, Tamil Nadu, India.

Corresponding Author: Professor D. Kannan, Madras Medical College, Institute of Surgical Gastroenterology, Rajiv Gandhi Government General Hospital, Chennai, Tamil Nadu, India; Ph: 09787387183/09444878183; Email: minnalraja@gmail.com

Received: 11 August 2014

Accepted: 10 September 2014

Published: 28 November 2014 mass were included in the study. The mean follow-up was six months. Using visual analogue scale score pain was analyzed both preoperatively and postoperatively. Endocrine and exocrine insufficiencies are also analyzed. Results: There was no 30-day mortality. Statistical analysis showed significant improvement of pain score. The improvement of pain score in the patients without head mass is comparable to the patients with head mass for whom Frey procedure was done. Though there is improvement in endocrine and exocrine insufficiency they are not statistically significant as per chi-square test. Conclusion: This study shows that even in the patients with no pancreatic head mass, the head coring pancreatico jejunostomy procedure described by Frey provides a better quality of life and better pain relief with acceptable morbidity and nil mortality. Head coring procedure can be therefore strongly recommended for pain relief even in pancreatitis without head mass.

Keywords: Chronic calcific pancreatitis, Frey procedure, Head coring, Non-head mass CCP, Pain score, Pancreatico Jejunostomy

\section{How to cite this article}

R Rajamahendran, Amudhan A, Prabhakaran R, Duraisamy B, Vellaisamy R, Kannan D, Chandramohan SM. Head coring for chronic calcific pancreatitis without pancreatic head mass: Shortterm outcome analysis. Int $J$ Hepatobiliary Pancreat Dis 2014;4:62-69.

Article ID: 100024IJHPDRR2014

doi:10.5348/ijhpd-2014-24-OA-12 


\section{INTRODUCTION}

Intolerable abdominal pain is the main cause which brings the patients with chronic calcific pancreatitis (CCP) to the surgeon. There are many causes of pain in chronic pancreatitis which include ductal hypertension [1], increased parenchymal pressure, perineural inflammation [2] or as a complication of the disease. There are various interventions available to relieve the pain in CCP like conservative and surgical management [3-5]. Based on the morphology of the gland resection and drainage are the two types of surgeries that are available $[6,7]$.

Of the chronic pancreatitis cases, $18-50 \%$ of patients present with an inflammatory head mass [6] and its resection was considered very essential to relieve the pain by removing the "pacemaker of pain" [8]. In 1987, Frey et al. reported a novel technique for patients with inflammatory head mass commonly known as Frey procedure in which local resection of the head of pancreas combined with longitudinal pancreaticojejunostomy (LR-LPJ) was done. It was found that Frey procedure provided excellent pain control in 90\% of the patients with low mortality and morbidity [9]. There are a sub group of patients who present with CCP without head mass with or without a dilated duct. Routine practice in those patients is to do lateral pancreaticojejunostomy known as modified Puestow procedure.

\section{AIM AND BACKGROUND}

Pancreatitis induced pain can be relieved adequately by removing the pacemaker, draining the major and branch ducts sufficiently, removing the stones in the duct and parenchyma around the head. The cored out tissue will be also available to rule out malignancy in pancreas. This study enlightens that since the head is the "pacemaker of pain" $[10,11]$ if we apply the same procedure of head coring for the patients without head mass there will be good pain control without added morbidity or mortality. Frey procedure was done in 80 patients who presented to us without pancreatic head mass. Short-term outcome analysis was done and results are analyzed by the statistical variables.

\section{MATERIALS AND METHODS}

\section{Patients and Methods}

This is a combined prospective and retrospective study was done at Rajiv Gandhi Government General Hospital by the Department of Surgical gastroenterology between 2010 and 2013, 140 patients with chronic calcific pancreatitis underwent Frey procedure for intractable abdominal pain. All patients had a detailed history and clinical examination. The diagnostic workup includes measuring the serum amylase, lipase, CA199 and ultrasonography (USG), upper gastrointestinal endoscopy, portal vein Doppler, computed tomography (CT) scan, and magnetic resonance cholangio pancreatography (MRCP). These patients presented to us with a typical history of abdominal pain that is present in the epigastrium and radiating to the back. We further evaluated and confirmed the diagnosis by looking at the pancreatic calcification or dilatation of main pancreatic duct on imaging (USG, CT scan, and MRCP). Head mass is defined by the presence of the mass in the head of pancreas with a anteroposterior head diameter was more than $35 \mathrm{~mm}$ in contrast-enhanced computed tomography (CECT) of abdomen [11, 12, 13].

Small or non-dilated duct is the name given if it measured $5 \mathrm{~mm}$ or less at neck [14]. Main duct was considered as dilated if it measured greater than $7 \mathrm{~mm}$ in its maximal diameter. Exocrine function of the pancreas was assessed by the presence or absence of steatorrhea. Steatorrhea is defined as frequency of more than three stools per day with nauseating smell and greasy consistency [15]. Pain was assessed using visual analogue scale (VAS) and frequency of pain attacks along with analgesic requirement. Surgery was offered to those patients who had visual analogue scale pain score more than 8.

\section{Patient Exclusions}

Of the 140 cases of chronic calcific pancreatitis those patients with head mass and pseudocyst in the head are eliminated from the study. We also eliminated the patients who failed to show alcohol abstinence. Patients who have completed at least six months follow-up alone were included in the study.

In that way, we selected only 80 patients who presented to us with chronic calcific pancreatitis without head mass (CECT abdomen showing head of pancreas anteroposterior diameter less than $35 \mathrm{~mm}$ ) and had regular follow-up for six months.

\section{Surgical Procedure}

The head coring procedure was performed exactly as described by Frey and Smith [16]. The coring was done at the head of pancreas after lay opening the major duct. The coring was continued without breaching the posterior pancreatic capsule. In most cases, we could identify the duct by aspiration method. Using Diathermy and Harmonic scalpel the head and uncinate process of pancreas were cored out. The amount of tissue cored was measured in grams. After perfect hemostasis, a loop of jejunum brought in Roux-en-Y fashion to pancreas and pancreaticojejunostomy using a continuous 3'o polyglactin in a single continuous layer. All the cored out pancreatic tissue was sent for histopathological examination. Most patients were discharged by 1oth postoperative day after suture removal. 


\section{RESULTS}

A total of 80 patients were analyzed. Of them 60 were male and 20 were female. The age of the patients varies between 13 to 58 years. The mean age and SD is 37 \pm 10.4 years (Figure 1). Regarding the etiology of chronic calcific pancreatitis, alcohol was associated in 58 patients and 22 patients were considered to be tropical calcific pancreatitis. (Table 1). Of the various complications in this group (Figure 2): Ten presented with diabetes mellitus, six presented with exocrine insufficiency, splenic vein thrombosis with fundal varices was seen in three patients. Pseudocyst in the tail of the pancreas was seen in seven patients. Pancreatic ascites was present in three patients and only two of them without head mass presented with jaundice. All the patients underwent CECT scan to look for calcifications and head mass (Figure 3). MRCP was done in two patients who presented with jaundice (Wadsworth syndrome) both of them had a tapering end of the distal CBD in the absence of head mass (Figure 4). Upper gastrointestinal endoscopy and portal venous Doppler was done for all patients. Only three patients who had splenic vein thrombosis on portal vein Doppler had fundal varices on endoscopy and diagnosed as sinistral portal hypertension. All the patients underwent Frey procedure as already described, amount of tissue cored was measured in grams. Average tissue coring done in the 80 patients is 3.8 grams (Figure $5 \mathrm{~A}-\mathrm{E}$ ).

Additional procedures like distal pancreatectomy with splenectomy was done in 10 patients - three patients who had sinistral portal hypertension, seven patients who had pseudocyst in tail of pancreas. Six patients who had small duct disease underwent Izbikis ' $V$ ' shaped opening of the duct along with head coring. For the two patients who had jaundice choledocho jejunostomy was done in one patient and the other patient had relief of jaundice after coring (Table 2). All the other patients underwent single layered mucosa to mucosa pancreaticojejunostomy using 3 'o polypropylene continuous sutures (Figure 5C-D)

No patient had major intraoperative complications. Mean blood loss is $150 \mathrm{~mL}$. Mean duration of surgery is three and half hours. There was no 30-day mortality. In this series, significant complications occurred in 10 patients. It included three with pulmonary complications, five with wound infection, one had gastric outlet obstruction due to jejunojejunal intussusception which was managed by laparotomy and one had pancreatic leak which settled after two months by conservative management (Table 3). The pulmonary complications that were mentioned include two patients with left lung basal atelectasis and one patient with aspiration pneumonia. Atelectasis was treated with intravenous deriphyllin, nebulization with bronchodilators and chest physiotherapy. Aspiration pneumonitis was treated with Antibiotics and bronchodilators. Wound infection cases underwent pus culture and sensitivity and appropriate antibiotics were added based on the antibiotic sensitivity. Four cases had Staphylococcus aureus positive in the culture test and one patient had E. coli and Kliebsiella grown in culture. One patient had jejunojejunal intussusception at the jejunojejunostomy site of anastomosis. The jejunojejunostomy was done in that case in an end to side fashion. The patient presented to us with history of pain abdomen and vomiting after

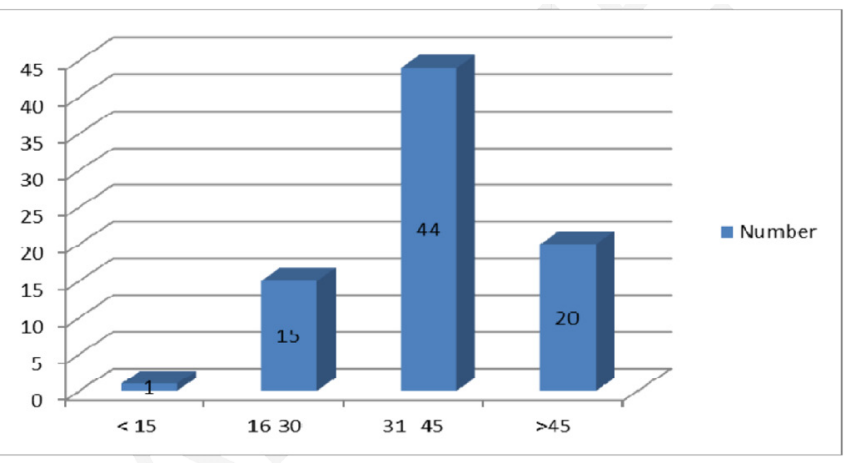

Figure 1: Age distribution of Chronic Calcific Pancreatitis without Head mass.

Table: 1: Etiology of Chronic Calcific Pancreatitis without Head mass

\begin{tabular}{lll} 
Cause & Number & Percentage \\
\hline Alcohol & 58 & $72.5 \%$ \\
Tropical and others & 22 & $27.5 \%$ \\
\hline
\end{tabular}

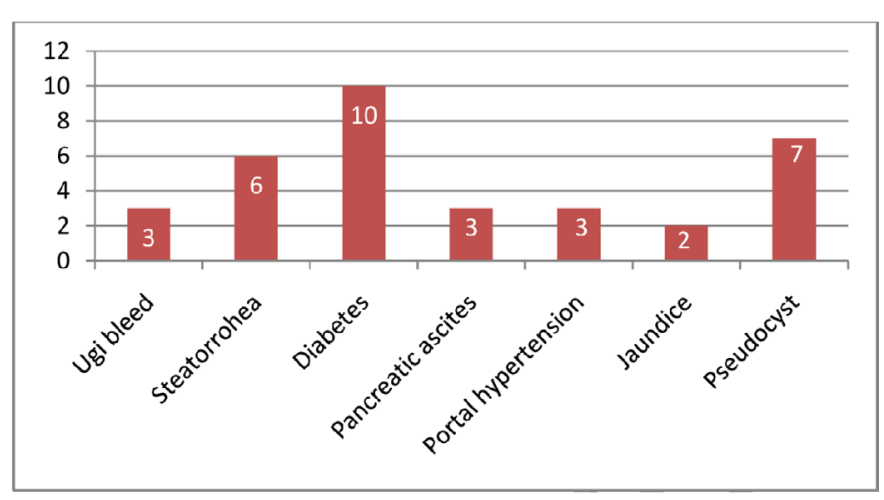

Figure 2: Complications of CCP without head mass.

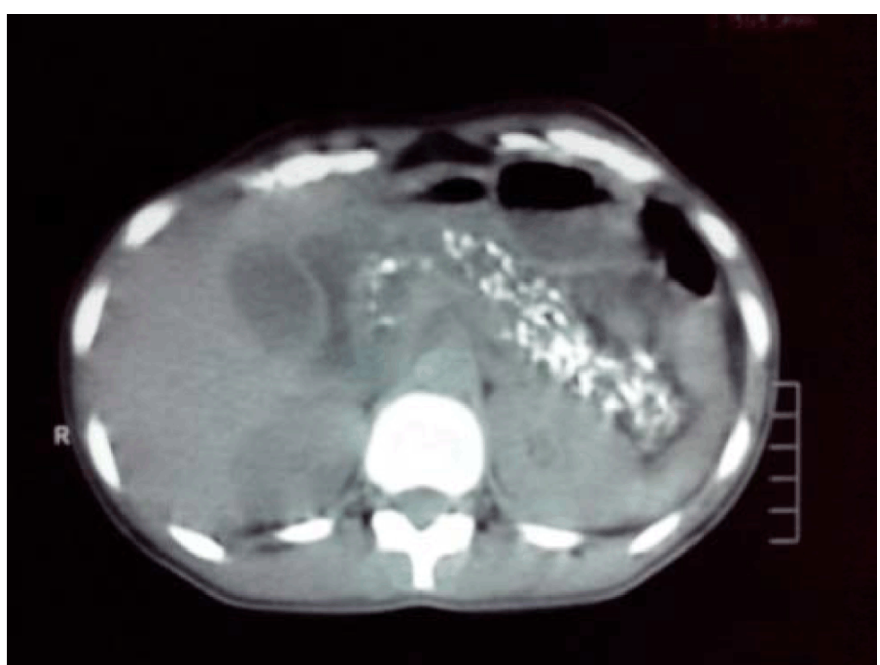

Figure 3: CECT abdomen showing diffuse calcification in head and body. 


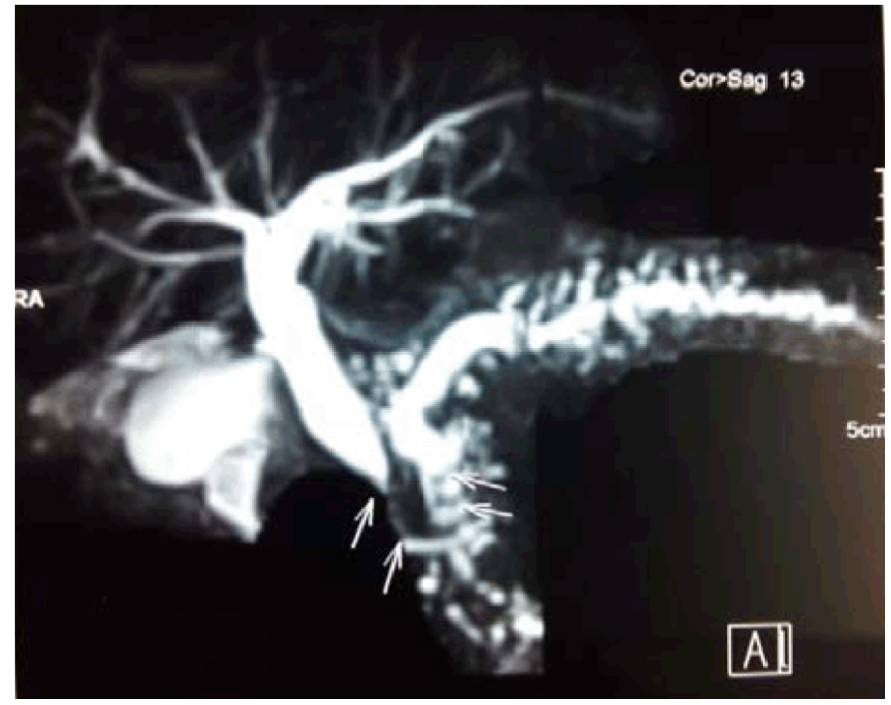

Figure 4: MRCP showing biliary stricture (Wadsworth syndrome).
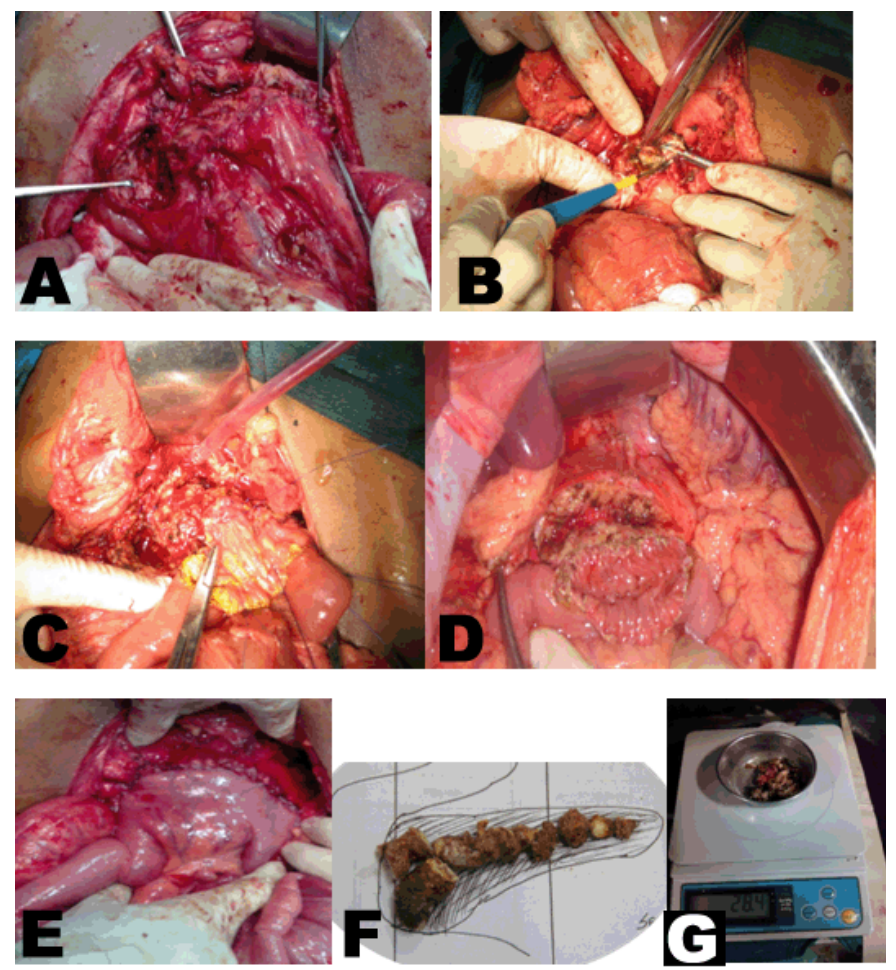

Figure 5: Intraoperative pictures: (A) Removal of stones, (B) Head coring and opening of duct, (C, D) Anastomosing the jejunum with pancreas, (E) Completed LR-LPJ, (F) Removed stones and (G) Cored tissue being weighed.

Table 2: Additional procedures performed

\begin{tabular}{lll}
\hline Features & Procedure & $\begin{array}{l}\text { Number of } \\
\text { cases (\%) }\end{array}$ \\
\hline $\begin{array}{l}\text { Pseudocysts in tail } \\
\text { of pancreas }\end{array}$ & $\begin{array}{l}\text { Frey+ Distal } \\
\text { pancreatectomy and } \\
\text { splenectomy }\end{array}$ & $7(8.75 \%)$ \\
$\begin{array}{l}\text { Sinistral portal } \\
\text { hypertension }\end{array}$ & $\begin{array}{l}\text { Frey+ Distal } \\
\text { Pancreatectomy and } \\
\text { splenectomy }\end{array}$ & $3(3.75 \%)$ \\
$\begin{array}{l}\text { Wadsworth } \\
\text { syndrome }\end{array}$ & Choledocho jejunostomy & $1(1.25 \%)$ \\
Small Duct disease & Izbikis with Head coring & $6(7.5 \%)$ \\
\hline
\end{tabular}

Table 3: Postoperative complications

\begin{tabular}{ll} 
Complications & Number of patients (\%) \\
\hline Wound infection & $5(6.25 \%)$ \\
Pulmonary complication & $3(3.75 \%)$ \\
Jejuno jejunal intussusception & $1(1.25 \%)$ \\
Pancreatic fistula & $\mathbf{1}(1.25 \%)$ \\
\hline
\end{tabular}

two months of surgery. When we did Gastrografin study, we found that there is cut-off at the level of upper jejunum with distension of stomach. The CECT scan of abdomen showed the presence of intussusception. For that patient, we did relaparotomy and did disconnection of jejunojejunostomy. A new anastomosis was done in a side to side fashion between the pancreatic limb of the jejunum and afferent limb of jejunum. Biopsy of the cored tissue obtained in all cases. Biopsy report, came as chronic pancreatitis, of only one patient showed evidence of malignancy, and the patient was referred to medical oncology for Gemcitabine based chemotherapy. The patient was under follow-up with us for six months. He did not develop any metastasis until six months. His CA19-9 level after six months was 10. All patients were followed-up for six months regularly in outpatient department and register was maintained about the pain score based on visual analogue scale (VAS) score, diabetic control (in terms of reduction in Hba1c and reduction in dose of insulin/OHA) or new onset diabetes, weight gain and about exocrine insufficiency.

On follow-up for six months period, 72 (90\%) had complete pain relief and $8(10 \%)$ patients on follow-up found to have VAS score of 8. Coeliac plexus blockade was given in the follow-up period if they do not respond for analgesics for a period of two months. Only those patients who had retractable pain after two months of analgesics were selected for CECT guided coeliac plexus blockade. Of the eight patients, only six needed coeliac plexus blockade and two patients were comfortable with analgesics. Of the 10 patients with diabetes 4 (40\%) of them improved in glycemic control with reduction of insulin dose and reduction in HBa1c after three months. Of the six patients with steatorrhea 4 (66\%) had improvement of symptoms. No patient developed new diabetes or steatorrhea in the six-month follow-up period. About 54 patients (67.5\%) developed a weight gain of more than $5 \mathrm{~kg}$ in six months (Table 4).

Using chi-square test, the variables analyzed showed statistically significant $p$ value for pain relief and there is no statistical significance in the glycemic control and steatorrhea (Table 4) With the data obtained the mean and SD for pain score before is 8.33 0.66 and the mean score and SD after surgery $1.14 \pm 0.47$. Using paired $t$-test $p$ value $<0.0001$, significant as per statisticians analysis (Table 5). 
Table 4: Follow-up of patients

\begin{tabular}{|c|c|c|c|c|c|}
\hline S. No. & Variable & Preoperative & Postoperative & Improvement (\%) & $p$ value \\
\hline 1 & Pain score $(>8)$ & $80(100 \%)$ & $8(10 \%)$ & $90 \%$ & $<0.00001$ \\
\hline 2 & $\begin{array}{l}\text { Diabetes mellitus } \\
\text { ( reduction in Hba1c and Insulin/ } \\
\text { OHA agents dose) }\end{array}$ & $10(100 \%)$ & $6(60 \%)$ & $40 \%$ & 0.29 \\
\hline 3 & $\begin{array}{l}\text { Steatorrhea (Increased stool } \\
\text { frequency }>3 \text { with oily nature) }\end{array}$ & $6(100 \%)$ & $2(44 \%)$ & $66 \%$ & 0.14 \\
\hline 4 & Weight gain $>5 \mathrm{~kg}$ after 6 months & - & 52 & $67.5 \%$ & - \\
\hline
\end{tabular}

Table 5: Analysis of preoperative and postoperative variables

\begin{tabular}{lllll}
\hline S. No. & Variables & Preoperative score & Postoperative values & $\boldsymbol{p}$ value \\
\hline 1 & Pain score & $8.33+0.66$ & $1.14+0.47$ & $<0.00001$ (significant) \\
\hline
\end{tabular}

Table 6: Various studies showing the outcome of Frey procedure

\begin{tabular}{llll} 
& Pain remission at end of follow-up (\%) & Average follow-up (months) & N \\
Frey and Amikura (1994) & 86.7 & 37 & 50 \\
Izbicki et al. (1995) & 89 & 17 & 22 \\
Ho and Frey (2001) & 88 & 38.4 & 75 \\
Falconi et al. (2006) & 88.8 & 60 & 40 \\
Pessaux et al. (2006) & 88 & 15 & 34 \\
Egawa et al. (2009) & 100 & 46 & 71 \\
Keck et al. (2010) & 62 & 43 & 50 \\
Negi et al. (2010) & 75 & 76.8 & 60 \\
\hline
\end{tabular}

\section{DISCUSSION}

Surgical intervention for chronic pancreatitis is the most effective therapeutic option for pain control and management of complications as per all studies. The main aim of the surgical treatment of chronic pancreatitis is to alleviate severe pancreatic pain and to manage pancreatitis-related loco regional complications. Although lateral pancreaticojejunostomy (Partington Rochelle) which had been practiced over three decades, it is clear that this is not a technique that solves all problems for patients with chronic pancreatitis.

Many of the patients who underwent LPJ had recurrence of pain, which was often attributed to persistence or relapse of the disease in the pancreatic head. So the symptomatic relief which was the demand by most of the patients were not met. It is only the symptomatic relief that we are aiming to achieve. The principle of Frey procedure is to decompress the branch ducts in the head of the pancreas, which is considered to be the pacemaker of the disease ("controller of inflammation") [17]. The pancreatic head region is excised almost in its entirety, leaving behind a bridge of pancreatic tissue about $1 \mathrm{~cm}$ wide, while a rim of pancreas (5 to $10 \mathrm{~mm}$ ) remains beside the duodenum and on the upper margin of the pancreatic head $[18,19]$. The pancreatic neck above the portal vein and superior mesenteric vein are left intact. Regarding the postoperative quality of life in terms of pain relief Frey procedure gives much better life. Frey procedure is accepted as a "patient friendly" procedure with zero mortality and a low morbidity rates [20]. Our mortality and morbidity is well within the acceptable range as that of Frey procedure for head mass chronic calcific pancreatitis (Table 6).

By doing surgery for chronic pancreatitis, we aim at achieving the complete pain relief and at the same time preserving the endocrine and exocrine function as much as possible. As per the data, $70-80 \%$ of the patients with varying follow-up after this procedure had good pain control [21, 22]. A few patients having poor pain outcome after surgery are multifactorial and may include inadequate drainage of head, neuropathic changes and unrecognized cancer [23]. An incidence of $10-20 \%$ of persistent recurrent symptoms has been reported following Frey procedure. A significant improvement in diabetes and exocrine function is seen following the decompression of the ductal system [24]. In our series, we had improvement in both endocrine and exocrine insufficiency though they are statistically not significant. 


\section{CONCLUSION}

This study shows that the head coring pancreaticojejunostomy procedure described by Frey provides a better quality of life and better pain relief with acceptable morbidity and nil mortality even in the patients with no pancreatic head mass. Head coring procedure can be therefore strongly recommended for pain relief even in pancreatitis without pancreatic head mass. Large scale RCTs must be done comparing the outcomes of LR-LPJ and LPJ alone for non-head mass chronic calcific pancreatitis in future.

$* * * * * * * * *$

\section{Author Contributions}

Rajamahendran Rajendran - Substantial contributions to conception and design, Acquisition of data, Analysis and interpretation of data, Drafting the article, Revising it critically for important intellectual content, Final approval of the version to be published

Anbalagan Amudhan - Analysis and interpretation of data, Revising it critically for important intellectual content, Final approval of the version to be published Prabhakaran R. - Analysis and interpretation of data, Revising it critically for important intellectual content, Final approval of the version to be published

Benet Duraisamy - Analysis and interpretation of data, Revising it critically for important intellectual content, Final approval of the version to be published

Rajendran Vellaisamy - Analysis and interpretation of data, Revising it critically for important intellectual content, Final approval of the version to be published

Kannan D. - Analysis and interpretation of data, Revising it critically for important intellectual content, Final approval of the version to be published

Chandramohan S.M. - Analysis and interpretation of data, Revising it critically for important intellectual content, Final approval of the version to be published

\section{Guarantor}

The corresponding author is the guarantor of submission.

\section{Conflict of Interest}

Authors declare no conflict of interest.

\section{Copyright}

(C) 2014 Rajamahendran Rajendran et al. This article is distributed under the terms of Creative Commons Attribution License which permits unrestricted use, distribution and reproduction in any medium provided the original author(s) and original publisher are properly credited. Please see the copyright policy on the journal website for more information.

\section{REFERENCES}

1. Ebbehøj N, Svendsen LB, Madsen P. Pancreatic tissue pressure: Techniques and pathophysiological aspects. Scand J Gastroenterol 1984 Nov;19(8):1066-8.

2. Bockmann DE, Buchler M, Malfertheiner P, Beger HG. Analysis of nerves in chronic pancreatitis. Gastroenterology 1988 Jun;94(6):1459-69.

3. Büchler MW, Binder M, Friess H. Role of somatostatin and its analogues in the treatment of acute and chronic pancreatitis. Gut 1994;35(3 Suppl):S15-9.

4. Carr-Locke DL. Endoscopic procedures in the treatment of pancreatic pain. Acta Chir Scand 1990 Apr;156(4):293-7.

5. Warshaw AL, Banks PA, Fernandez-del Castillo C. AGA technical review: Treatment of pain in chronic pancreatitis. Gastroenterology 1998 Sep;115(3):76576.

6. Traverso LW, Kozarek RA. Pancreaticoduodenectomy for chronic pancreatitis. Ann surg 1999;236:429-36.

7. Bradley EL 3rd. Long-term results of pancreatojejunostomy in patients with chronic pancreatitis. Am J Surg 1987 Feb;153(2):207-13.

8. Traverso LW. The surgical management of chronic pancreatitis: The Whipple procedure. Adv Surg 1999;32:23-39.

9. Pessaux P, Kianmanesh R, Regimbeau JM, et al. Frey procedure in the treatment of chronic pancreatitis: Short-term results. Pancreas 2006 Nov;33(4):354-8.

10. Lillemoe KD, Ball CG. Pancreaticoduodenectomy for Chronic Pancreatitis. Fischer Mastery of surgery 6th edition. Josef E. Fischer (ed). Philadelphia, USA. 2012 pp. 1401.

11. Yeo CJ, Matthews JB, McFadden DW, Pemberton JH, Peters JH. Chronic Pancreatitis. Shackelford's Surgery of Alimentary tract 7th ed. 2013 pp. 1138. Table 89-5.

12. Strate T, Taherpour Z, Bloechle C, et al. Long term follow-up of a randomized trial comparing the Beger and Frey procedures for patients suffering from chronic pancreatitis. Ann Surg 2005 Apr;241(4):5918.

13. Amudhan A, Balachandar TG, Kannan DG, et al. Factors affecting outcome after Frey procedure for chronic pancreatitis. HPB (Oxford) 2008;10(6):47782.

14. Shrikhande SV, Kleeff J, Friess H, Büchler MW. Management of pain in small duct chronic pancreatitis. J Gastrointest Surg 2006 Feb;10(2):227-33.

15. Rault A, SaCunha A, Klopfenstein D, et al. Pancreaticojejunal anastomosis is preferable to pancreaticogastrostomy after pancreaticoduodenectomy for long term outcomes of pancreatic exocrine function. J Am Coll Surg 2005 Aug;201(2):239-44.

16. Frey CF, Smith GJ. Description and rationale of a new operation for chronic pancreatitis. Pancreas 1987;2(6):701-7.

17. Egawa S, Motoi F, Sakata N, et al. Assessment of Frey procedures: Japanese experience. J Hepatobiliary Pancreat Sci 2010 Nov;17(6):745-1.

18. Frey CF, Smith GJ. Description and rationale of a new operation for chronic pancreatitis. Pancreas 1987;2(6):701-7. 
19. Frey CF, Amikura K. Local resection of the head of the pancreas combined with longitudinal pancreaticojejunostomy in the management of patients with chronic pancreatitis. Ann Surg 1994 Oct;220(4):492-504.

20. Izbicki JR, Bloeche C. Drainage operation as therapeutic principle of surgical organ saving treatment of chronic pancreatitis. Chirurug 1997;68(9):865-73. [Article in German].

21. Frey CF, Amikura K. Local resection of the head of the pancreas combined with longitudinal pancreaticojejunostomy in the management of patients with chronic pancreatitis. Ann Surg 1994 Oct;220(4):492-504.
22. Keus E, van Laarhoven CJ, Eddes EH, Masclee AA, Schipper ME, Gooszen HG. Size of the pancreatic head as a prognostic factor for the outcome of Beger's procedure for painful chronic pancreatitis. Br J Surg 2003;90(3):320-4.

23. Markowitz JS, Rattner DW, Warshaw AL. Failure of symptomatic relief after pancreaticojejunal decompression for chronic pancreatitis. Strategies for salvage. Arch surg1994;129(4):374-9.

24. Nealon WH, Thompson JC. Progressive loss of pancreatic function in chronic pancreatitis is delayed by main pancreatic duct decompression: A longitudinal prospective analysisof the modified Puestow procedure. Ann Surg 1993 May;217(5):458-66.

\section{ABOUT THE AUTHORS}

Article citation: Rajamahendran R, Amudhan A, Prabhakaran R, Duraisamy B, Vellaisamy R, Kannan D, Chandramohan SM. Head coring for chronic calcific pancreatitis without pancreatic head mass: Short-term outcome analysis. Int J Hepatobiliary Pancreat Dis 2014;4:62-69.

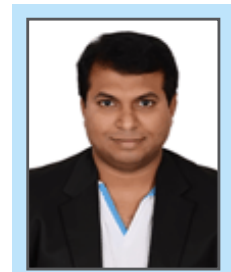

Rajamahendran Rajendran is Junior Resident in Surgical Gastroenterology, Institute of Surgical Gastroenterology at Madras Medical College, Rajiv Gandhi Government General Hospital, Chennai. He earned undergraduate degree (MBBS) from Government Kilpauk Medical College, Chennai and postgraduate degree (MS General Surgery) from Government Kilpauk Medical College, Chennai. He has Acquired MRCS (Edinburgh) in the Year 2008, Completed Fellowship in Minimal Access Surgery in the Year 2008 under Amasi. He has published a case report of Embryonal rhabdomyosarcoma Liver in a 16 year old boy in International Journal of Hepatobiliary and Pancreatic Diseases and authored 8 books for undergraduates and 3 books for postgraduate students. His research interests include pancreatic cancer and chronic calcific pancreatitis. Email: minnalraja@gmail.com

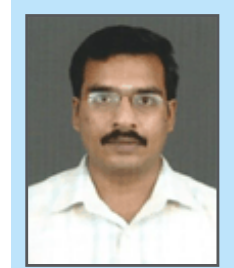

Amudhan Anbalagan is the Senior Assistant Professor in Surgical Gastroenterology, Institute of Surgical Gastroenterology at Madras Medical College, Rajiv Gandhi Government General Hospital, Chennai. He earned undergraduate degree (MBBS) from Stanley Medical College, Chennai and postgraduate degree (MS General Surgery) from Madras Medical College, Chennai and MCh Surgical Gastroenterology from Stanley Medical College, Chennai. He has published four research papers in national and international academic journals. His research interests include hepatobiliary and pancreatic surgeries. He has special interest in laparoscopic surgery.

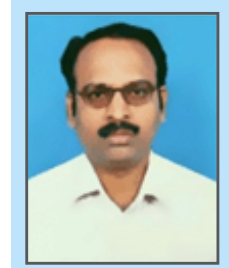

Prabhakaran $\mathbf{R}$ is Assistant Professor at Madras Medical College in Surgical Gastroenterology, Institute of Surgical Gastroenterology Rajiv Gandhi Government Hospital, Chennai, India. He earned the undergraduate degree (MBBS) and Postgraduate degree (MS General Surgery) from Madurai Medical College, Madurai and superspeciality degree MCh Surgical Gastroenterology (Gold Medalist) from Stanley Medical College, Chennai, India. He has published two research papers in national and international academic journals. His research interests include hepatobiliary and pancreatic surgery. He is specialized in advanced laparoscopic gastrointestinal surgery. 


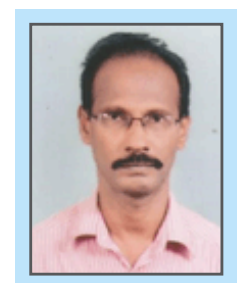

Benet Duraisamy is Assistant Professor in Surgical Gastroenterology, Institute of Surgical Gastroenterology at Madras Medical College, Rajiv Gandhi Government General Hospital, Chennai, India. He earned undergraduate degree from Stanley medical College, Chennai, India and MCh Surgical gastroenterology from Madras Medical College, Chennai, India. His research interests include hepatobiliary, upper gastrointestinal and colorectal surgeries. He has special interest in gastrointestinal malignancies.

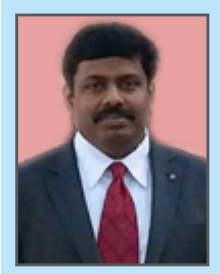

Rajendran Vellaisamy is Junior Resident in Madras Medical College in Surgical Gastroenterology, Institute of Surgical Gastroenterology. He earned undergraduate degree from Madurai Medical College and postgraduate degree from Kilpauk medical College, Chennai, India. His research interests include chronic pancreatitis, hilar cholangiocarcinoma and liver resection.

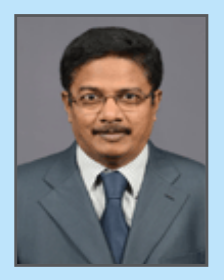

Kannan D. is Professor of Surgical gastroenterology in Institute of Surgical Gastroenterology, Madras Medical College, Rajiv Gandhi General Hospital, Chennai, India. He completed his MCh Surgical gastroenterology from Madras medical College, He qualified his FRCS from UK. He has published a lot of articles in National and International Journals. His special field of interest includes liver resection and pancreatic cancer surgeries. He has done more than 200 Whipple's Procedure in his carrier.

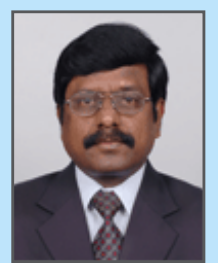

Chandramohan S. M. is the Director and Head, Institute of Surgical Gastroenterology, Madras Medical College, Rajiv Gandhi General Hospital, Chennai, India. Presently, he is the Secretary, Indian Association of Surgical Gastroenterologis. He completed his MS General Surgery (Gold Medal) from Tanjore Medical college, Tanjore, India. He completed MCh Surgical gastroenterology from Madras Medical College, He has published more than 50 articles in National and International Journals. He has authored Upper gastrointestinal Chapters in a lot of textbooks. His special field of interest includes Upper GI surgery. He has done a lot of research and innovative works in corrosive stricture esophagus. He has great records in dealing with complex upper gastrointestinal works. His special field of interest include Gastric Cancer in India.

Access full text article on other devices

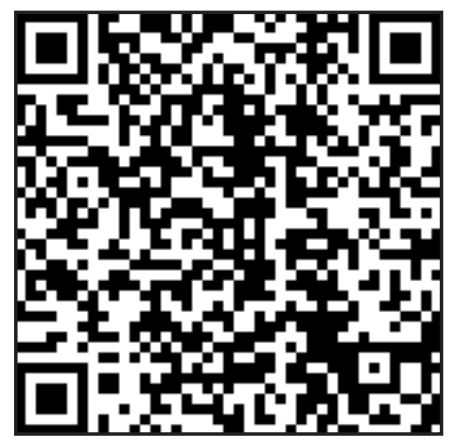

Access PDF of article on other devices

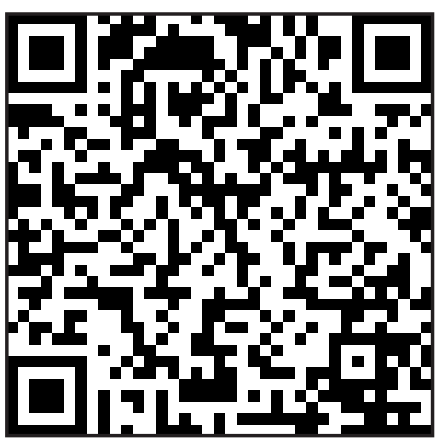

